\title{
SKILLS GAP - SOLUTION MAY BE WITH DIGITAL SKILLS ACCELERATOR PROJECT
}

\author{
A. Soeiro', F. Uras' ${ }^{2}$, C. Royo ${ }^{2}$ \\ ${ }^{1}$ Universidade Porto (PORTUGAL) \\ ${ }^{2}$ EUCEN (SPAIN)
}

\begin{abstract}
Much research has been carried out on the digital divide in the labour market, most notably the gap between the demand for employees with high level information and communication technologies (ICT) skills and the low availability. However, in today's labour market, it is estimated that $90 \%$ of all jobs require ICT skills [1] since rapid innovation in ICT is leading to "the need for digital skills in nearly all jobs where ICT complements existing tasks" [2]. Nevertheless, 47\% of the European Union population is not properly digitally skilled and this is even more noticeable in Poland, where $54 \%$ of the population have no or low digital skills [3]. For example, Poland ranks last among OECD countries with less than $20 \%$ of all workers using office computer or mobile software daily [4].
\end{abstract}

For these reasons, the Digital Skills Accelerator (DSA) project aims to put learners in the driving seat of their own skills development. The goal of the project is clear: define the digital skills that should be prioritized by current and future cohorts of HE students, and create a self-directed multi-media learning system that students can access to bolster their skills in specific areas.

In order to achieve this goal, the project intends to:

- Produce a Digital Skills Report (IO1) identifying the most valuable digital skills required professionally and for civic engagement.

- Create an Online Self-Assessment Tool (IO2) enabling students to identify their digital skills' profile and map a personalized learning pathway.

- Develop the Essential Digital Skills Toolkit (IO3), an open, online modular training course allowing students to update their skills in the key areas.

- Produce a series of Motivation and Engagement Videos (IO4) as an essential component of the recruitment and learning process.

- Test and optimize the resources before disseminating them widely to ensure strong use among the target groups.

The DSA model is based heavily on the concepts of user based design and so it is only reasonable that the project should integrate as much user participation as possible at all stages, from design to execution to evaluation. It involves Higher Education (HE) institutions, Vocational Education and Training (VET) institutions and wider stakeholders will participate in a digital skills report, teaching staff from HE \& VET institutions. HE learners will participate in user testing and in video case studies and HE and VET institutions and wider stakeholders will participate in multiplier events. The DSA project will produce the knowledge, resources and social capital (commitment from key actors) to enable the introduction of the Digital Skills and Competences model to our HE and VET institutions, and through them to present and future generations of digital confident citizens.

Keywords: Skills, gap, self-assessment, toolkit, digital.

\section{INTRODUCTION AND MOTIVATION}

A significant aspect and less well documented, but equally important in light of recent developments, is the use - and misuse - of digital communications in the civic and social spheres, the impact on personal and professional development and wider democratic value. While more than half of European Union citizens use social media daily, very few have engaged in any learning activities designed to ensure their safe and productive use. Due to the seriousness of this diagnostic some attempts have been made to include the competences related with civic, social and cultural engagement and to verify the acquisition of these competences with a proper assessment framework [5]. 
The overall problem is that progress in technology has outpaced the ability of our institutions to develop suitable teaching systems to facilitate its best use. This resistance is felt particularly in higher education, where several factors have inhibited the integration of digital skills teaching, not least the lack of ICT skills among Higher Education teaching staff and a natural resistance to incorporating unproven digital pedagogies into the classroom.

Therefore, the objectives of the Digital Skills Accelerator project intends to place students in the driving seat of their own skills development. The goals of the project are clear: to define the digital skills that should be prioritized by current and future cohorts of HE students and create a self-directed multi-media learning system that students can access to bolster their skills in specific areas.

In order to achieve these targets the project will produce four outputs. The first tries to facilitate the knowledge sharing among key stakeholders to produce a Digital Skills Report identifying the most valuable digital skills required professionally (in the workplace) and for civic, social and cultural engagement. The second attempts to create an Online Self-Assessment Tool enabling students to identify their digital skills' profile and map a personalized learning pathway. The third output is the development of an Essential Digital Skills Toolkit based on an open online modular training course allowing students to update their skills in the key areas. The last consists in the production of a series of Motivation and Recruitment Videos as an essential component of the recruitment and learning process. These outputs will be tested before disseminating the tools to facilitate wider use among the target groups.

The target groups were selected from the expected stakeholders concerning the outputs produced. DSA aims to reach mainly students of universities and colleges (HE institutions) preparing to enter the workforce. By demonstrating a robust digital skillset to future employers and using technology to "learn how to learn" they may become more competitive in the labour market and may boost their employment prospects in the short term and long term.

Other additional target groups include the HE Institutions who need practical, cost-effective solutions for providing digital skills training for their students, the businesses and employers at local and regional level who need to hire graduates who contribute productively by selecting the right technology for the right job and solving problems in innovative ways and civic minded organizations who need to find new ways to increase engagement of young people in civic and social impact projects

The project addressed the international dimension of the goals and of the stakeholders. The Digital Single Market strategy of the European Commission acknowledges the huge potential of increased digital competency. It may transform the economic and civic life in Europe and highlights the importance of digital skills training to achieve this change. Given that these issues are so embedded in EU and national policy it makes sense that any effort to drive these subjects forward should also take place on this scale.

In addition to these consequences the project, while working transnationally, can optimise processes of best practice exchange, ensuring improved results in the identification of pedagogic strategies. The project can achieve an in depth knowledge of the target group, procedural rigour and digital expertise, which will make the resources not only relevant in participating countries, but scalable across Europe.

This project also intends to complement existing European programmes, specifically the Digital Single Market initiative and the Poland Coalition for Digital Jobs. It will reach other target groups and use other methods. The innovation derives from the selection of the survey groups, from the focus on cognitive and technological skills and from the forms of the training delivery method.

Despite the huge volume of research on digital skills at EU and national level, according to the OECD, "very few countries have developed strategies to foster the acquisition of 21 st century skills in formal education." Moreover, whereas primary and secondary schools are slowly but surely introducing digital skills in the curricula, this is too little and too late for today's current and future cohorts of university students and actual needs of population. For instance, if current HE graduates are entering the workforce and if they lack the skills then their career and personal development will suffer negatively.

It is true that several large-scale digital training platforms have emerged to provide digital skills training [6], [7]. Most of these platforms have limitations since these are available mostly in English, can be costly, focus on the technological (rather than cognitive) skills and are long. These characteristics can be overwhelming for students who have no clear idea of where their career will develop. The DSA project, however, will try to create a more focussed toolkit, based on regional needs, to prioritize key 
transversal digital skills and to integrate the critical, the problem solving and the social-empathy skills required to use technology more effectively. In fact, the nature of $\mathrm{HE}$ role in providing critical and analytical thinking makes these tools the ideal forum for blending learning of this type into a coherent product for prospective learners.

The quality of the DSA project outputs is a major concern. Therefore, the project will support digital skills not only in content but also by the means of the delivery. Unlike many online learning courses which allow learners' pick and choose which modules appeal most, in this project the users start with a simple to use (but rigorously developed) self-assessment tool. This will establish a recommended pathway through the toolkit, giving learners an improved balance between personalization and structure inside a user-friendly learning environment.

\section{METHODOLOGY}

The DSA project methodology was developed around the identified unique objectives. The adopted approach reflects international best practice in project management. It integrates high levels of participation from the adopted target groups and has a robust monitoring and impact evaluation structure. As already mentioned the work plan was developed to achieve four intellectual outputs and consists of three transversal work programs and of four multiplier events. Each partner assumes responsibility for one of the intellectual outputs and/or a transversal work program. The coordinator will use these detailed related strategies, the corresponding calendar of activities and information to evaluate the partners' contributions to the project progress.

All the intellectual outputs were developed using a theory of change analysis enabling the determination of the best and realistic path to achieve the desired impacts. Starting dates of the tasks are sequential to avoid load saturation of the partnership with new activities. It is planned that there will be two digital skills research reports to set up the knowledge base for the subsequent outputs and to ensure a regional focus and commitment to change from key regional actors.

Then, with the analysis of the reports and with the related frameworks generated, the basis of the development of the self-assessment tool can be drafted. This tool represents the first step of the DSA project path. The learners will use an interactive self-assessment tool to identify their current digital skills profile. The following step will be the development of an open education resource comprising the essential digital skills toolkit. This comprehensive course, where learners move through in accordance with their own digital skills improvement plan, will employ a variety of pedagogic and technological strategies, in order to reinforce the "learning by doing" approach. Finally, the motivation and engagement videos will involve capturing the experience of learners who have been through the DSA project process and share their learning experiences.

Some activities will run throughout the DSA project to ensure the it remains on track focusing on the quality and relevance of the project objectives intended impacts. The first is the project management using the project handbook, the work plan and the approved budget. The second is the dissemination and sustainability that will ensure the expected participation of target groups and uptake of the outputs. The last is the quality management and evaluation ensuring the minimum quality standards.

A multiplier event will be held in each country in the form of a national conference to ensure that the projects' intellectual outputs are promoted to reach wider audiences as possible. The events will include a presentation of the project, will engage participants to understand the importance of mainstreaming digital skills education and to generate commitments to teaching essential digital skills .

The monitoring and evaluation will be done the active participation of all partners. The impact evaluation strategy will include milestones to track progress based around the deliverables, indicators to measure quality in outputs and processes, impact evaluation indicators generated from user participation and testing and corrective measures from partners. These elements will be addressed in monthly partnership meetings online and will be presented in quarterly progress reports. In addition, an external evaluator will be hired to provide independent oversight and verification of results.

\section{RESULTS}

On completion, the DSA project will have produced the knowledge, resources and social capital, like commitment from key actors, to enable the introduction of a digital skills and competences model to $\mathrm{HE}$ and VET institutions. This model, when implemented, may provide present and future generations with citizens possessing digital confidence and competences. This effect may generate improved 
employability and professional prospects for learners, more innovative and digitally competent students and more resilient regional economies.

Using a careful theory of change analysis, the DSA project tangible outputs have been designed to serve as catalysts and tools to enable broader and deeper learning outcomes in terms of knowledge, of skills and of behaviour. Although these outputs have a more intangible nature these will be monitored and measured throughout the project.

The concrete tangible results are a Project Management Handbook, a Digital skills research report identifying and prioritizing information related with supply and demand for digital competences, a SelfAssessment tool, an Essential Digital Skills Toolkit consisting of a training course, a set of Motivation and Engagement Videos (IO4), an Integrated Dissemination Strategy, a Sustainability Strategy, an Impact Evaluation Strategy and two External Evaluations prepared by an external evaluator.

Other expected benefits are that HE and VET institutions and other stakeholders will acquire working habits in terms of digital skills, that teaching staff in HE and VET institutions will integrate digital skills into their courses, HE learners will develop digital competences and skills for application in their professional lives and that stakeholders and policy makers will gain greater awareness about the relevance of digital competences.

\section{CONCLUSIONS}

The DSA project may present a solution to the identified skills gap of youth, of unemployed and of large part of active population. In fact, the digital skills are mentioned in several national and European studies as a major issue in terms of competitiveness and productivity. Taking into account that the lack of other types of skills, that make part of the set that needs upgrading in Europe, are difficult to alleviate through training the digital competencies can use education to improve the level of performance. This project presents concrete tools to attend the need for digital competences.

The combination of the digital tools to identify the current and important digital competencies, to produce training courses dedicated to self-assessment using ICT methods and to have a dissemination digital strategy is, in itself, an evidence that may a relevant project. DSA project has an adequate methodology, a dedicated group of partners with complementary capacities and a proper research strategy. The testing and validation of the tools will also allow the optimization of the resources and the necessary quality assurance.

\section{ACKNOWLEDGEMENTS}

This paper is a summary of the project proposal KA203-03857 of Higher Education Strategic Partnerships program financed by the European Commission. The subprogram of the project is the development of innovation and the project will last for 24 months. The project is coordinated by Zachodniopomorski Uniwersytet Technologiczny w Szczecinie (Poland) and the partners are Universidad de Alcala (Espana), Canice Consulting Limited (Northen Ireland), Momentum Marketing Services (Ireland) and EUCEN (Belgium).

\section{REFERENCES}

[1] International Data Corporation, "Worldwide Internet of Things Services Forecast, 2017-2021", www.idc.com, accessed 9May2018 (2016).

[2] Digital Single Market, "Open Data”, https://ec.europa.eu/digital-single-market/en/open-data, accessed 9May18 (2017).

[3] EC Digital Single Market publications, "Country Information - Poland", https://ec.europa.eu/digital-single-market/en/country-information-poland, accessed 9May18 (2014).

[4] OECD Library, "Digital Economy Outlook 2015", https://data.oecd.org/ict/internet-access.htm, accessed 9 May18 (2015).

[5] CALOHEE - Comparing Achievement of Learning Outcomes in Higher Education in Europe, "Working-Paper-for-Civic-Social-and-Cultural-Engagement", www.calohee.eu, accessed on 9May18 (2017). 
[6] Lynda training platform, "Linkedin training", https://www.lynda.com, accessed 9May18 (2017).

[7] UDEMY, "Get skills in business, tech, and personal development", https://www.udemy.com, accessed 9 May18 (2015). 